\title{
Archivo Histórico de Río Pardo: fuentes de preservación de la memoria histórica y lingüística ${ }^{1}$
}

\section{(Historical Archive of Rio Pardo: sources of preservation of historical and linguistic memory)}

\author{
LEICI LANDHERR MOREIRA \\ leicimoreira@hotmail.com \\ Universidade Federal de Santa Maria (UFSM)
}

Fecha de recepción: 20 de noviembre de 2018

Fecha de aceptación: 29 de julio de 2019

Resumen: Este trabajo tiene el objetivo de discutir la importancia de los documentos del Archivo Histórico Municipal de Río Pardo (AHMRP) como fuentes de preservación de la memoria histórica y lingüística, considerando el documento como parte integrante del patrimonio cultural brasileño. Se presenta la edición facsímil y semidiplomática de un documento del AHMRP, la copia de la Provisión Real de 1809 que establece la primera división del estado de Rio Grande do Sul, seguida de estudio lingüístico de las variantes gráficas. De ese modo, evidenciamos que los documentos oficiales del AHMRP actúan también como principal testimonio del pasado lingüístico de Río Pardo desde el siglo XIX.

Palabras clave: Documentos oficiales. Ediciones. Archivo Histórico. Memoria.

Abstract: This paper aims to discuss the importance of documents from the Municipal Historical Archive of Rio Pardo (AHMRP) as sources of preservation of historical and linguistic memory, considering the document as an integral part of the Brazilian cultural heritage. We present the facsimile and semidiplomatic edition of an AHMRP document, the copy of the Royal Provision of 1809 that establishes the first division of the state of Rio Grande do Sul, followed by a linguistic study of the graphic variants. In this way, we

${ }^{1} \mathrm{O}$ presente trabalho foi realizado com apoio da Coordenação de Aperfeiçoamento de Pessoal de Nível Superior - Brasil (CAPES) - Código de Financiamento 001. 


\section{LEICI LANDHERR MOREIRA}

show that the official documents of the AHMRP also act as the main testimony of the linguistic past of Rio Pardo since the 19th century.

Keywords: Official documents. Editions. Historical Archive. Memory.

\section{Considerações iniciais}

A cidade de Rio Pardo possui uma relevância histórica e social muito grande embora pouco valorizada, por vezes ignorada e, até mesmo, desconhecida por grande parte de sua população. Junto com Porto Alegre, Rio Grande e Santo Antônio da Patrulha, foi uma das primeiras vilas criada na primeira divisão do estado pela provisão de 07 de outubro de 1809. Suas raízes históricas, no entanto, remontam à criação estratégica de um povoado em virtude do Tratado de Madri em 1750 (Vogt; Romero 2010). O acordo de fronteiras, assinado em Madri por D. João V, rei de Portugal, e por D. Fernando VI, rei da Espanha, consistiu no esforço para pôr fim à disputa entre Portugal e Espanha acerca de seus limites coloniais. Inicialmente, os portugueses não demonstraram interesse pelas terras ao sul do Brasil, conhecidas como "terra de ninguém". Somente no século XVIII, Portugal foi atraído pelas terras pertencentes então à Espanha em razão do comércio estabelecido na região do rio da Prata e do gado existente nos campos do Rio Grande do Sul. Esse motivo deu início ao litígio entre a Coroa Portuguesa e Espanhola pelo que viria a ser a cidade de Rio Pardo, até aquele momento território dos índios Tapes (Vogt; Romero 2010).

A demarcação da nova fronteira trouxe à Comandância Militar o CapitãoGeneral da Capitania do Rio de Janeiro Gomes Freire de Andrade que ordenou a construção do Forte Jesus, Maria José em Rio Pardo como local estratégico devido à sua localização na margem esquerda da confluência dos rios Pardo e Jacuí. Segundo Meister (2017), "na busca pela segurança, a população civil que já circulava, formada principalmente por tropeiros, comerciantes e açorianos, começou a aproximar-se da região do Forte, dando origem ao povoado", que se tornou um dos principais núcleos urbanos e centro econômico-comercial do Rio Grande do Sul na primeira metade do século XIX. Essa história está preservada na memória que perpassa a arquitetura antiga e os registros escritos do Arquivo Histórico da cidade.

Neste artigo, apresentamos as edições fac-similar e semidiplomática, seguidas de estudo linguístico, da cópia da Provisão Real de 1809 que estabelece a primeira divisão do estado do Rio Grande do Sul, até então chamado de Província de São Pedro. Pretendemos olhar para esse documento do Arquivo Histórico Municipal de Rio Pardo, doravante AHMRP, como fonte de preservação da memória não só no que se refere aos fatos históricos, mas 
Archivo Histórico de Río Pardo: fuentes de preservación de la memoria histórica...

também pela possibilidade de estudo da língua portuguesa escrita no Brasil no início do século XIX, sobretudo, em textos não-literários. Desse modo, tecemos uma breve consideração geral sobre a instituição "Arquivo Histórico", o Arquivo Histórico de Rio Pardo, e sobre a importância do documento enquanto patrimônio cultural de uma sociedade, povo ou nação. A seguir pontuamos a contribuição da Crítica Textual para a salvaguarda e recuperação do patrimônio cultural escrito através de tipos de edição monotestemunhais de acordo com a forma de estabelecimento do texto. Também apontamos as normas constitutivas de nossas edições fac-similar e semidiplomática para, então, apresentá-las na íntegra. Por fim, realizamos um breve estudo linguístico tocante à análise das variações gráficas da ortografia portuguesa, que representa a memória da língua.

\section{O Arquivo Histórico e o patrimônio cultural}

A palavra Arquivo, do latim archivum, derivado do grego archêion, foi usada pela primeira vez em língua portuguesa no século XVI como "lugar ou móvel onde se guardam documentos" (Cunha 2012: 58). Nos estudos atuais de Arquivologia designa principalmente uma "instituição ou serviço que tem por finalidade a custódia, o processamento técnico, a conservação e o acesso a documentos" (Arquivo Nacional 2005: 27). De modo geral, um documento funciona como uma "unidade de registro de informações, qualquer que seja o suporte ou formato" (2005: 73). Segundo Bellotto (2002: 17), “o documento é o registro legitimado do ato administrativo ou jurídico, consequência, por sua vez, do fato administrativo ou jurídico". Destarte, o documento do Arquivo público se apresenta como único testemunho da organização administrativa de uma sociedade em séculos passados e das ações que regulavam os costumes de outras épocas, daí sua relevância histórica e social.

No entanto não são raras as vezes em que ouvimos que um Arquivo Histórico se tornou o depósito de pilhas de papéis em desuso oriundos da administração de uma instituição pública. Nessas condições, apaga-se um fato importante: o documento do Arquivo é uma das únicas formas de registro do passado de uma sociedade, é o que garante a preservação da memória de uma comunidade, nação ou povo. Por esse motivo o documento é um dos elementos que compõe o Patrimônio Cultural brasileiro, segundo o Art. 216 da Constituição de 1988:

Constituem patrimônio cultural brasileiro os bens de natureza material e imaterial, tomados individualmente ou em conjunto, portadores de referência à identidade, à 


\title{
LEICI LANDHERR MOREIRA
}

\author{
ação, à memória dos diferentes grupos formadores da \\ sociedade brasileira, nos quais se incluem: (EC \\ $\left.\mathrm{n}^{\circ} 42 / 2003\right)$ \\ I - as formas de expressão; \\ II - os modos de criar, fazer e viver; \\ III - as criações científicas, artísticas e tecnológicas; \\ IV - as obras, objetos, documentos, edificações e demais \\ espaços destinados às manifestações artístico-culturais; \\ $\mathrm{V}$ - os conjuntos urbanos e sítios de valor histórico, \\ paisagístico, artístico, arqueológico, paleontológico, \\ ecológico e científico (2016: 126, grifo nosso).
}

$\mathrm{Na}$ ausência de uma prática de Educação Patrimonial visível e apoio das políticas governamentais, o patrimônio cultural, na forma representativa de documento, pode estar condenado à extinção. Por isso a UNESCO criou o Programa Memória do Mundo (Memory of the World) em 1992 no intuito de garantir a preservação do patrimônio documental representativo de boa parte do patrimônio cultural mundial através de técnicas apropriadas; auxiliar o acesso universal ao patrimônio documental e aumentar a divulgação do conhecimento da existência e significação do patrimônio documental (Cardia 2017).

A despeito do número crescente de candidaturas de acervos, museus e Arquivos para serem inscritos no registro nacional do programa, o que vemos, de fato, na maior parte das cidades brasileiras é a perda parcial de fontes documentais em consequência da falta de recursos financeiros, da carência de profissionais qualificados, e do descarte, por vezes obrigatório, haja vista a falta de espaço físico e dos métodos de conservação e preservação pouco eficientes. Sem o acesso à informação em virtude dos danos irreversíveis acometidos ao suporte material, as fontes primárias de consulta para a reconstrução historiográfica e para o estudo da língua portuguesa escrita em sincronias passadas se perdem para sempre.

Lobo (2009: 307) aponta que na "segunda metade da década de 1990 inaugura, nos estudos histórico-diacrônicos do português brasileiro, uma fase que se caracteriza pela laboriosa tarefa de construção de uma filologia de textos escritos no Brasil"'. Na Bahia, os arquivos e acervos foram fundamentais para a reconstrução histórica do processo de formação do português brasileiro a partir

2 Em 1997, no I Seminário Para a História Do Português Brasileiro, por iniciativa de Ataliba Teixeira de Castilho, formulou-se um projeto de pesquisa de âmbito nacional, o "Projeto pra a História do Português Brasileiro - PHPB, que se constitui de corpora diacrônicos de edições de documentos de natureza vária, escritos no Brasil, a partir do século XVI (Lobo 2009: 306). 
Archivo Histórico de Río Pardo: fuentes de preservación de la memoria histórica...

da edição semidiplomática de seus documentos. No Rio Grande do Sul, em 2011 com a criação do projeto "Português Histórico do Rio Grande do Sul", "um banco de dados de registros escritos produzidos no estado que busca reunir material representativo da produção escrita de vários estágios da língua" (Costa; Keller 2017: 38), os documentos de Arquivos do estado vêm ganhando visibilidade. Para este artigo, consideremos, então, o Arquivo Histórico de Rio Pardo, "o guardião da memória, dos direitos, deveres e privilégios de toda uma sociedade" 3 nos primórdios do século XIX.

\subsection{Arquivo Histórico Municipal de Rio Pardo}

O Arquivo Histórico Municipal de Rio Pardo Biágio Soares Tarantino possui um acervo documental riquíssimo e de importância histórica e social muito grande. Sua criação data da constituição dos Departamentos Culturais do município no contexto da campanha de nacionalização do Estado Novo (19371945), quando da instituição de agências oficiais de preservação do patrimônio nacional (Costa; Remedi 2013: 36-37)4. Nessa conjuntura, segundo Costa e Remedi (2013: 36), Biágio Soares Tarantino (1903-1973), cidadão rio-pardense, historiador autodidata e defensor local do patrimônio contribuiu significativamente no processo de monumentalização de Rio Pardo, lutando pela criação dos organismos culturais no município em defesa dos "valiosos testemunhos de nossas caras tradições" (Tarantino 1955: 2).

$\mathrm{Na}$ administração de Ernesto Protásio Wunderlich, prefeito de Rio Pardo entre 1936 e 1947, foram, então, criadas as repartições públicas: Museu Barão de Santo Ângelo, Biblioteca Municipal, Arquivo Histórico, Diretório Municipal de Geografia e o Conservatório de Música. Biágio Tarantino tornou-se o responsável por esses espaços e se dedicou a sensibilizar a comunidade acerca da importância da preservação da memória de Rio Pardo. Ao Arquivo Público Municipal foi legado o seu nome: "Arquivo Histórico Municipal de Rio Pardo Biágio Soares Tarantino", célebre homenagem ao defensor do patrimônio literário, arquivístico e museológico da cidade.

O AHMRP existia de fato, mas não legalmente, uma vez que só foi criado oficialmente em 29 de dezembro de 1992 pela Lei Municipal no 162. Em 1994, o projeto "Memória, História e Educação Patrimonial: revitalização do arquivo

3 Expressão usado por Gomes (2012: 391) para designar o Arquivo Histórico Municipal de Viamão, também localizado no Rio Grande do Sul.

4 Trata-se da criação das agências: Inspetoria de Monumentos Nacionais (IPM), pelo Decreto $\mathrm{n}^{\circ}$. 24.735, de 14 de julho de 1934, e pela posterior implementação, em 1937, do Serviço do Patrimônio Histórico e Artístico Nacional (SPHAN), pelo Decreto n ${ }^{\circ} .25$, de 30 de novembro de 1937 (Costa; Remedi 2013: 51). 


\section{LEICI LANDHERR MOREIRA}

histórico do município de Rio Pardo - projeto REVITA-AHMRP”, apoiado pela Secretaria de Estado da Cultura (SEDAC-RS), Universidade de Santa Cruz do Sul (UNISC) e Prefeitura Municipal de Rio Pardo (Marques et all: 2006) produziu o inventário dos documentos existentes no Arquivo e realizou restauros e organização por fundos documentais. Entretanto tal projeto perdurou somente até 1997, quando da mudança da administração. No momento presente, há cerca de 100 mil documentos em manuscritos dos períodos colonial, imperial e republicano, compreendendo uma variedade de tipologias documentais desde os registros oficiais da Casa da Câmara Municipal, mapas, plantas, periódicos, iconografia, até as cartas e registros pessoais.

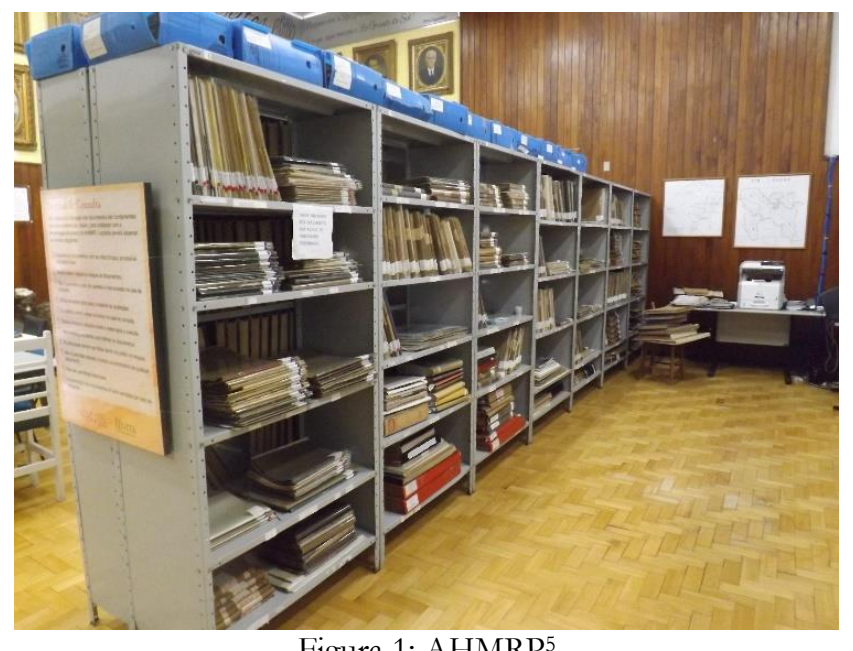

Figura 1: AHMRP5

\footnotetext{
${ }^{5}$ Todas as fotos pertencem ao arquivo pessoal da autora.
} 
Archivo Histórico de Río Pardo: fuentes de preservación de la memoria histórica...

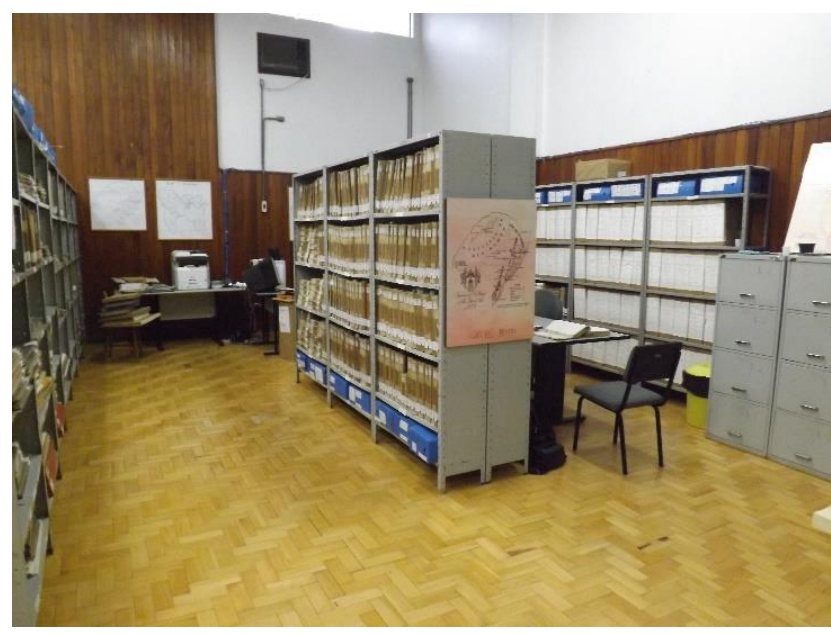

Figura 2: AHMRP

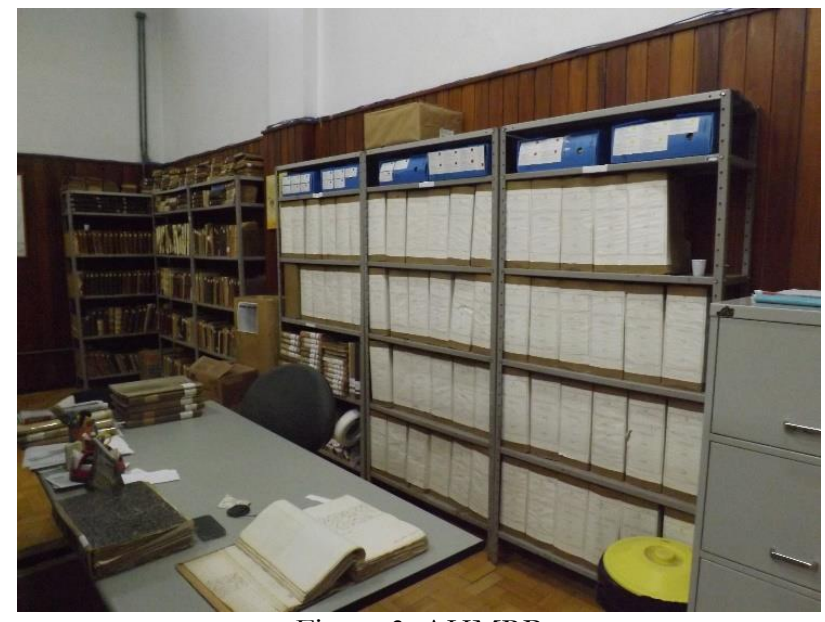

Figura 3: AHMRP 


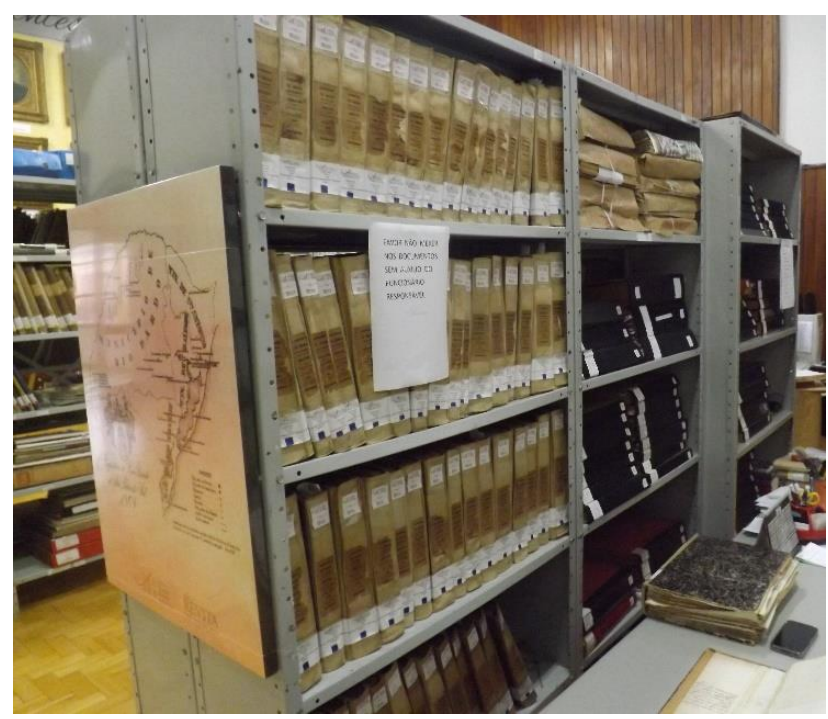

Figura 4: AHMRP

Dado o encerramento do projeto REVITA e a ausência de profissionais qualificados, os documentos sucumbem à ação do tempo, sofrendo modificações exógenas derivadas da corrupção do material por conta da umidade e principalmente dos insetos (Cambraia 2005: 2). É nesse contexto que a Crítica Textual aparece como uma ferramenta que propicia a preservação das informações e a sobrevivência da memória histórica e linguística através da tarefa laboriosa de edição do texto.

\section{A Crítica Textual e a preservação dos documentos de Arquivo}

Segundo Auerbach (1970: 11), a edição crítica de textos é até hoje considerada por muitos eruditos como a forma mais nobre e mais autêntica da Filologia. Dentro desse campo muito amplo, cabe à Crítica Textual, o mais antigo e tradicional método da Filologia, a laboriosa tarefa de restituição da forma genuína dos textos, sua fixação e estabelecimento, ou seja, a edição (Cambraia 2005: 13). De acordo com Cambraia (2005: 19), "a contribuição mais evidente e importante da crítica textual é a recuperaşão do patrimônio cultural escrito de uma dada cultura". De fato, a edição de um documento manuscrito contribui para sua preservação, uma vez que assim se assegura a salvaguarda da informação do texto mediante a publicação em novos suportes materiais, ao mesmo tempo que aumenta a longevidade dos documentos genuínos, dado que 
Archivo Histórico de Río Pardo: fuentes de preservación de la memoria histórica...

não há mais necessidade de manipulação do suporte, evitando, assim, o desgaste físico.

Em se tratando de textos não literários monotestemunhais, dos quais não há cópias ad infinitum, podem ser atribuídos quatro tipos de edições baseados no grau de mediação empreendido pelo crítico textual ao fixar a forma do texto: fac-similar, diplomática, paleográfica e interpretativa (Cambraia 2005: 91-107). A edição fac-similar, também chamada de fac-símile, fac-similada ou mecânica, apoia-se no grau zero de mediação, pois se faz da reprodução da imagem de um testemunho por intermédio de meios mecânicos como a fotografia. Entretanto, como o acesso ao texto ocorre de forma praticamente direta, a leitura é limitada, porque o texto pode ser consultado somente por especialistas, tendo em vista a exigência da capacidade de leitura de uma escrita original. Não obstante, diante das intempéries que acometem os acervos, ocasionando a destruição de documentos como ocorreu no incêndio do Museu Nacional no Rio Janeiro em 2 de setembro de 2018, o fac-símile é o único tipo de edição que pode refletir para o mais alto grau os aspectos internos e externos do testemunho genuíno.

Já a edição diplomática, de um grau baixo de mediação, consiste na transcrição conservadora de todos os elementos presentes no manuscrito genuíno (sinais abreviativos, sinais de pontuação, paragrafação, translineação, separação vocabular etc.) como se fosse a cópia do mesmo. A edição paleográfica, semidiplomática ou diplomática-interpretativa, por sua vez, exige um grau médio de mediação, já que no processo de reprodução do testemunho genuíno, o editor realiza modificações adequando o texto a um público menos especializado que não seria capaz de decodificar determinadas características originais. Por isso realiza o desdobramento de sinais abreviativos, inserção ou supressão de elementos por conjuntura, dentre outros procedimentos. Por fim, na edição interpretativa, de grau máximo de mediação admissível, o editor também realiza o desenvolvimento de abreviaturas e conjecturas, além da uniformização gráfica e intervenções que aproximam o texto da suposta forma genuína, possibilitando o acesso ao texto mais apurado por um público mais amplo.

Dentre os tipos de edição mencionados, modernamente é a edição semidiplomática ou diplomático-interpretativa que tem se sobressaído na edição de documentos para o estudo da história da língua portuguesa (Cambraia 2005: 96). A seguir, apresentamos a edição semidiplomática, precedida pela edição fac-similar, da cópia da Provisão Real de 1809 que estabelece a primeira divisão do estado do Rio Grande do Sul, selecionada no Livro do Termo de Criação da 


\section{LEICI LANDHERR MOREIRA}

Vila de Rio Pardo (LTCVRP), lotado no AHMRP. Para tal edição, adotamos os preceitos normativos:

a) Caracteres alfabéticos: transcrever como caracteres romanos redondos, reproduzindo-se as diferenças de módulo. Uniformizar os alógrafos contextuais segundo a forma mais moderna. Quando houver mais de um tipo de caractere no modelo (como, p. ex., capitulares), informar em nota.

b) Sinais abreviativos: desenvolver todos (inclusive a nota tironiana $\langle 2\rangle$, que representa a conjunção aditiva $e$ ) com base nas formas por extenso presentes no modelo, transcrevendo em itálico os caracteres acrescentados em substituição ao sinal abreviativo.

c) Diacriticos: transcrever uniformizando os sinais segundo sua forma atual (mas mantendo seu uso tal qual no modelo).

d) Sinais de pontuação: transcrever fielmente segundo as formas presentes no modelo.

e) Caracteres de leitura duvidosa: transcrever entre parênteses redondo simples ().

f) Caracteres de leitura impossivel: transcrever como pontos dentro de colchetes precedidos pela cruz † (o número de pontos é o de caracteres não legíveis estimado).

g) Caracteres riscados: transcrever entre chaves duplas $\{\{$ \}\}.

h) Caracteres apagados: informar em nota quais seriam.

i) Caracteres modificados: informar em nota a forma primitiva.

j) Caracteres nas entrelinhas: transcrever, já no ponto do tempo pertinente, entre parênteses uncinados duplos $<<$ $>>$.

1) Caracteres nas margens: transcrever, no ponto do texto pertinente, entre parênteses uncinados simples seguidos de chaves simples $<\{\}>$; quando não fizer parte do texto, informar em nota.

m) Separação vocabular (intra- e interlinear): reproduzir fielmente.

n) Paragrafação: reproduzir fielmente.

o) Inserçôes conjecturais: inserir elementos por força do contexto entre parênteses uncinados simples $<>$ e por desgaste do suporte entre colchetes simples []. 
Archivo Histórico de Río Pardo: fuentes de preservación de la memoria histórica...

p) Supressões conjecturais: transcrever erros por repetição entre colchetes duplos [[ ]]; transcrever erros de outra natureza entre chaves simples \{\} .

q) Mudança de fólio, face e coluna: informar na margem de cabeça, em itálico e entre colchetes simples: [].

r) Mudanças de punho: informar em nota.

s) Mudanças de tinta: informar em nota.

t) Qualquer outra particularidade: informar em nota.

u) Numeração de linha: inserir na margem externa, contanto de $5 \mathrm{em} 5$, de forma contínua em todo o texto (Cambraia 2005: 129).

\subsection{Edição fac-similar}

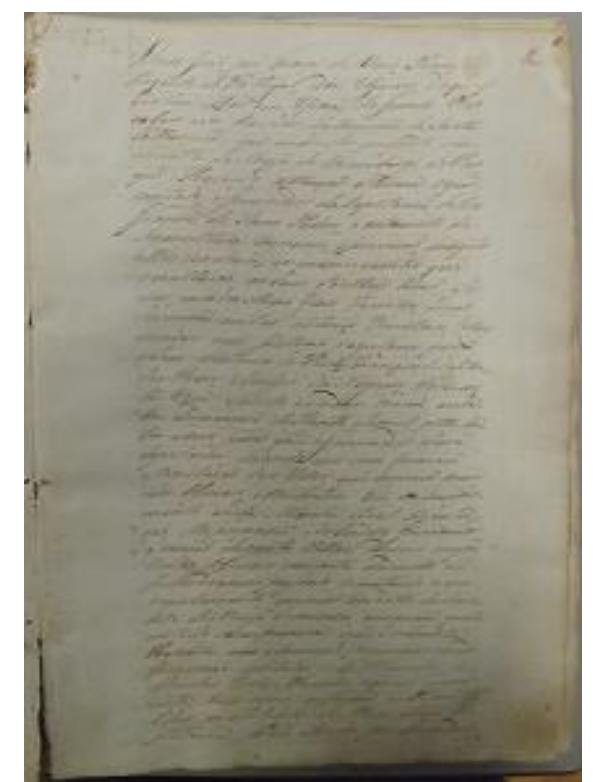

Figura 5: fac-símile de documento do AHMRP 
LEICI LANDHERR MOREIRA

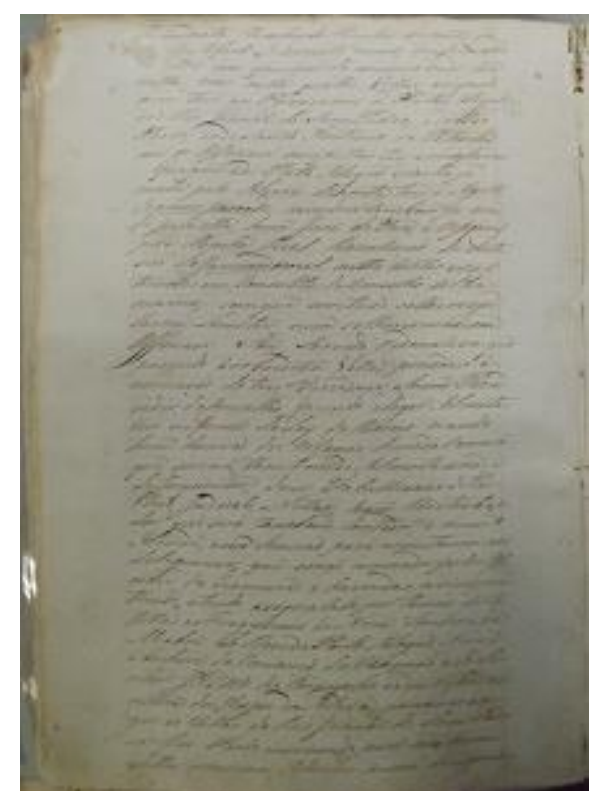

Figura 6: fac-símile de documento do AHMRP

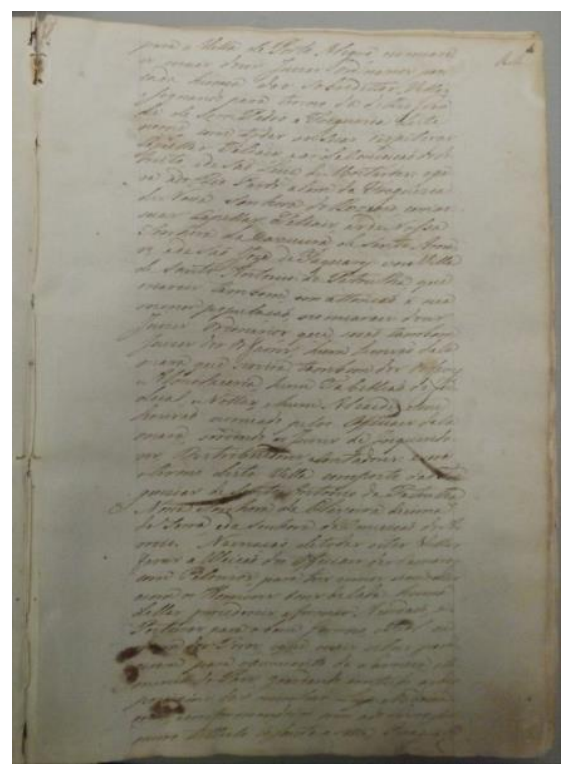

Figura 7: fac-símile de documento do AHMRP 
Archivo Histórico de Río Pardo: fuentes de preservación de la memoria histórica...

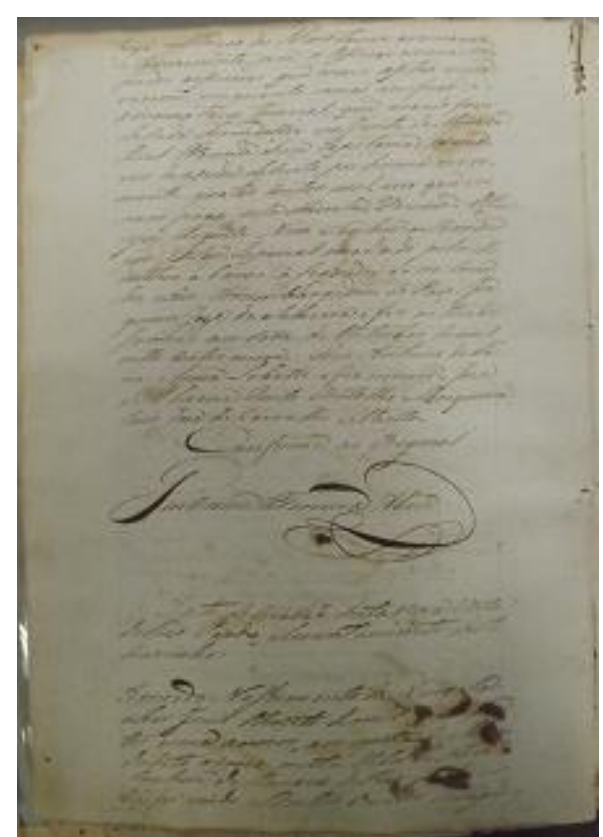

Figura 8: fac-símile de documento do AHMRP

\subsection{Edição semidiplomática}

Data: 7 de outubro de 1809

Cota: Arquivo Histórico Biágio Soares Tarantino (LTCVRP)

Tipo documental: Provisão Real

Assunto: Provisão real que estabelece a primeira divisão do estado do Rio Grande do Sul em quatro vilas: Porto Alegre, Rio Grande de São Pedro, Rio Pardo e Santo Antônio da Patrulha.

$$
\begin{array}{lc}
<\{\text { AHMRP }\}>6 & <\{2\}>7 \\
<\{000001\}>^{8} & <\{\text { Retro }\}>9 \\
\text { Dom Joaõ, por Graça deDeos, Principe }
\end{array}
$$

[f.2.r]

${ }^{6}$ Consta na margem esquerda do fólio. Anotação à lápis que fora efetuada posteriormente por outro punho.

${ }^{7}$ Consta na margem direita do fólio. Anotação à lápis que fora efetuada posteriormente por outro punho.

${ }^{8}$ Consta na margem esquerda do fólio. Anotação à lápis que fora efetuada posteriormente por outro punho.

${ }^{9}$ Consta na margem direita do fólio. Anotação à lápis que fora efetuada posteriormente por outro punho. 
LEICI LANDHERR MOREIRA

Rigente de Portugal, e dos Algarves d'aquem edalem Mar em Africa, de Guine. Faço saber avós Ouvidor daComarca deSanta

5 Catharina: que sendo-Me prezente em consulta daMeza do Dezembargo doPaço que havendo attençaõ aterme repre $=$ zentado oGovernador daCapitania do Rio Grande deSam Pedro, o aumento de -

10 Agriculttura, comercio epovoaçaõ, comque ella seachava, eos inconvinientes que rezultaraõ aobem do Meu Rial Ser viço, eaos dos Meos fieis vassallos, denaõ haverem emtaõ extenço Tirritorio, Villas

15 criadas com Justicas regulares para obom rigimen da Paiz, tranquilidade dos Povos, edicizaõ dos Nigocios Forences. Eu fora servido expidir ordem nada= tta dedezanove deAgosto demil outto cen $=$

20 tos eceis, para que oGovernador dessa Capitania, deacordo com vosco formace aregulaçaõ das Villas que conviece criar, seos Oficiaes e Destritos: Que emcumpri= mento desta Minha Rial Rezulu=

25 çaõ, Me perpozera o sobreditto Governador a criação dequatro Villas edeseus compe $=$ tentes Oficiaes emconta dedezoito de $=$ Julhodoanno passado, remetendo ovosso regulamento, eparecer em datta de deze $=$

30 sete deMayo domesmo, comquem quase emtudo secomformava; eque a sobredita Proposta com algumas pequenas modificaçoins apontadas pelo Procurador da Minha Coroa e Fazenda, aquem se dera

35 vista hera mui comforme ao $\mathrm{Bem} \mathrm{Pu}=$ blico, eá utilidade do Povosdessa $\mathrm{Ca}=$ pitania: Fui levado por Imediata Imediata Rezuluçaõ Minha devinte se $<\{\underline{\text { tte }}\}>^{10}$ deAbril docorrente anno conforman

40 doMe com oparecer da mencionada con sulta, criar nella quatro Villas erigindo como taes as Povoaçoins de Porto Alegre,

${ }^{10}$ Consta na margem esquerda do fólio, escrita por outro punho. 
Archivo Histórico de Río Pardo: fuentes de preservación de la memoria histórica...

ado Rio Grande de SamPedro, a do Rio

Pardo, eadeSanto Antonio da Patrulha,

45 com os Officiaes competentes e necessarios.

Epurque ade Porto Alegre seacha ja

criada pelo Alvará devinte tres deAgosto

doanno passado, havendoce tambem ja cria-

do para ella, um Juiz deFora e Orffaons

50 pela Minha Rial Rezuluçaõ de vinte

seis deJaneirodemil outto centos eseis, tomada emconsulta doConselho Ultramarino; semque comtudo selherregu-

lacem limites nem selhenomiacem

55 Officiaes: Sou servido ordenar=vos: que paçando á sobreditta Villa, procedais á= nomiaçaõ detres Viriadores, ehum procurador doConcelho, fazendo eleger Almota $=$ ceis na forma daLey do Reino, criando

60 hum Escrivaõ dos Orfaons, humda Camara que servirá tambemde Almotaceria, e de Inquiridor, dous Tabelliains doPublico, Judicial, eNottas; hum Distribuidor que será tambem Contador, e hum

65 Alcaide, eseu Escrivão para executarem as diligencias, que seraõ nomiados pelos Oficiaes daCamara: e havendo-o asim praticado, etendo asignalado por termo desta Villa as Freguezias deNossa Senhora da

70 Madre de Deos dePorto Alegre, Nossa Senhora daConceiçaõ deViamaõ, adoSe $=$ nhor Jezus do Triunpho, eadeNossa $\mathrm{Se}=$ nhora dos Anjos da Aldeia, passareis aeri= gir as Villas do Rio Grande de Sam Pedro

75 edo Rio Pardo, enomiando para cada huma dellas os mesmos Oficiaes acima designados para a Villa de Porto Alegre, nomiare $=\langle\{2\}>11$ [f.3.r] is mais dous Juizes Ordinarios para $\quad<\{$ Retro $\}>12$ cada huma das sobreditas Villas,

80 e signando para termo do de Rio Gran

${ }^{11}$ Consta na margem direita do fólio. Anotação à lápis que fora efetuada posteriormente por outro punho.

12 Consta na margem direita do fólio. Anotação à lápis que fora efetuada posteriormente por outro punho. 


\section{LEICI LANDHERR MOREIRA}

de de SamPedro a Freguezia deste nome, em todas as suas respetivas Capellas Filiais eas daConceição doEstreito, edeSaõ Luiz deMostardas: epa-

85 ra adoRio Pardo além da Freguezia da Nossa Senhora do Rozario, com assuas Capellas Filiais, as deNossa Senhora daCaxueira de Santo Ama= ro, edeSaõ Joze de Taquary: e naVilla

90 deSanto Antonio daPatrulha, que criareis tambem, em attençaõ á sua menor população, no miareis dous Juizes ordinários, que seraõ tambem Juizes dos Orfaons, hum Escrivaõ daCa

95 mara que servira tambem dos Orfaons; Almotaceria, ehum Tabelliaõ do $\mathrm{Ju}=$ dcial, eNottas, ehum Alcaide eseu Escrivaõ nomiado pelos Oficiaes daCa mara, servindo os Juizes de Inquirido-

100 res, Distribuidores, eContadores: eserá otermo desta Villa composto dasFreguezias de Santo Antonio daPatrulha, Nossa Senhora daOliveira decima daSerra, edaSenhora daConceiçaõ doA=

105 rroio. Nacriaçaõ detodas estas Villas fareis aElleiçaõ dos Oficiaes das Camaras com Pelouros, para tres annos ecom elles ecom os Homens bons decada huma dellas procedereis aformar Acordaõs, e

110 Posturas para obom Governo, $[\dagger \ldots . .]^{13}$ $[\dagger \ldots . .]^{14}$ dos Povos, eque mais uteis pare $=$ cerem para oaumento da Lavoura eComercio do Pais goardando emtudo asdesposicioins das minhas Leys e Ordena-

115 çoins, conformandovos com ado Livro pri= meiro tittulo cessenta e sete Paragrafo treze naElleiçaõ dos Almotaceis: enomeareis [f.3.v] intrinamente para os Oficiaes acima re= firidos aspessoas que mais aptas vospa-

120 recerem, emquanto senaõ virificar, $\mathrm{a}=$

13 Trecho manchado por tinta.

${ }^{14}$ Trecho manchado por tinta. 
Archivo Histórico de Río Pardo: fuentes de preservación de la memoria histórica...

arremataçaõ trienal que mando fazer

decada humdelles naJunta daMinha

Rial Fazenda dessa Capitania: evence $=$

reis deajuda decusto por huma ves so $=$

125 mente quatro centos mil reis que vos

ceraõ pagos pela Minha Fazenda. OPrin=

cipe Rigente Nosso Senhor oMandou

per Seu Expicial mandado pelos Mi-

nistros a baixo assignados doseu Conce-

130 lho, eseos Dezembargadores do Paço. Joa-

quimJoze daSilveira ofes no Rio de

Janeiro aos sete de Outubro demil

outto centos enove. Luis Antonio deFa-

Ria eSouza Lobatto ofes escrever= Joze

deOliveira Pinto Botelho eMosqueira

135 Luis Joze deCarvalho eMello=

Comforme ao Original

Guilherme ferreira Abreu

\subsection{Estudo linguístico}

A ortografia da língua portuguesa, ao longo da sua evolução, passou por diferentes fases. Os primeiros textos escritos em português apresentavam uma grafia próxima à oralidade, haja vista a tentativa de representar foneticamente os sons das palavras que escreviam. Posteriormente, já no Renascimento, as grafias latinas e gregas sobrelevam-se à escrita fonética, e abundam encontros consonantais (escripto, nocte), consoantes duplas e de grupos como $c h, p h, r h$, th. Tais ortografias, fonética e etimológica (ou pseudo-etimológicas) perduram até 1904, quando Gonçalves Viana publica "Ortografia Nacional” com vistas à uniformização gráfica.

Foram, então, estabelecidos três períodos da ortografia portuguesa: 1. período fonético, que coincide com o período do português arcaico, por isso se estende até o século XVI; 2. período etimológico, que se estende do século XVI até 1904 com a Ortografia Nacional, de Gonçalves Viana; 3. período simplificado ou das reformas ortográficas, de 1904 até os dias atuais (Coutinho: 1976). A Provisão Real de 1809 compõe-se de exemplos de variações gráficas próprias a cada uma dessas fases:

\begin{tabular}{|l|l|l|}
\hline \multicolumn{1}{|c|}{ Variação grafofonética } & \multicolumn{1}{c|}{ Variação etimológica } & \multicolumn{1}{c|}{ Variação gráfica livre } \\
\hline Deos (1.1, 70) & Catharina (1. 5) & prezente (1. 5) \\
\hline Rigente $(1.2,127)$ & attençaõ $(1.7,91)$ & Meza (1. 6) \\
\hline inconvinientes (1. 11) & ella (1. 11, 49) & Dezembargo (1. 6) \\
\hline
\end{tabular}




\begin{tabular}{|c|c|c|}
\hline Rial $(1.12,24,50,123)$ & vassallos (1. 14) & reprezentado $(1.7-8)$ \\
\hline Meos (1. 13) & $\begin{array}{l}\text { Villas (1. 14, 22, 26, 41, } \\
74,79,105)\end{array}$ & rezultaraõ (1. 12) \\
\hline Tirritorio (1. 14) & datta $(1.18-19,29)$ & conviece (1. 22) \\
\hline Paiz (1. 16) & sobreditto (1. 25) & Rezuluçaõ (1. 24-25) \\
\hline dicizaõ (1. 17) & anno $(1.28,39,48)$ & $\begin{array}{l}\text { selherregulacem (1. 53- } \\
54 \text { ) }\end{array}$ \\
\hline Nigocios (1. 17) & Mayo (1.30) & nomiacem (1.54) \\
\hline expidir (1. 18) & hera (1.35) & paçando (1.56) \\
\hline $\operatorname{seos}(1.23,130)$ & nella (1. 41) & Jezus (1. 72) \\
\hline $\begin{array}{l}\text { Oficiaes (1. 23, 27, 67, 76, } \\
98,106,118)\end{array}$ & Officiaes $(1.45,55)$ & Triunpho (1. 72) \\
\hline Destritos (1. 23) & $\begin{array}{l}\text { Villa (1. 56, 77, 89, } \\
\text { 101) }\end{array}$ & Rozario (1. 86) \\
\hline $\begin{array}{l}\text { Rezuluçaõ (1. 24-25, 48, } \\
50)\end{array}$ & $\begin{array}{l}\text { hum }(1.57,60,61,63, \\
96,97,122)\end{array}$ & Caxueira (1. 88) \\
\hline taes (1. 42) & Ley (1. 59) & $\begin{array}{l}\text { Freguezias (1. 69, 101- } \\
102 \text {, }\end{array}$ \\
\hline Officiaes $(1.45,55)$ & Tabelliains (1. 62) & Freguezia $(1.81,85)$ \\
\hline purque (1. 46) & Triunpho (1. 72) & Pais (1.113) \\
\hline nomiaçaõ (1. 57) & dellas $(1.76,109)$ & cessenta (1.116) \\
\hline Viriadores (1. 57) & huma $(1.79,108,124)$ & ceraõ (1.126) \\
\hline dous $(1.62,78,92)$ & Capellas $(1.83,87)$ & Expicial (1. 128) \\
\hline Tabelliains (1. 62) & Taquary (1.89) & $\begin{array}{l}\text { Dezembargadores (1. } \\
130)\end{array}$ \\
\hline Caxueira (1. 88) & Nottas (1.97) & fes $(1.131,133)$ \\
\hline goardando (1.113) & Elleiçaõ $(1.106,117)$ & \\
\hline desposicioins (1.113-114) & annos (1.107) & \\
\hline Ordenaçoins (1. 114-115) & elles (1.106) & \\
\hline refiridos (1.118-119) & Leys (1.114) & \\
\hline virificar (1. 120) & tittulo (1. 116) & \\
\hline Expicial (l. 128) & delles (l. 122) & \\
\hline
\end{tabular}

Quadro 1: As variações grafemáticas constantes na Provisão Real de 1809

\section{Considerações finais}

Ao longo do texto, destacamos a importância da instituição pública Arquivo Histórico como guardiã de registros escritos acerca de atos administrativos e jurídicos sobre uma sociedade, nação ou povo. Do mesmo modo, enfatizamos 
Archivo Histórico de Río Pardo: fuentes de preservación de la memoria histórica...

o valor desses registros na forma de documentos representativos do patrimônio cultural brasileiro. De acordo com Queiroz (2016: 216), "Documentos sob a guarda de acervos públicos e/ou privados constituem-se como verdadeiros patrimônios sócio-linguístico-histórico-culturais". Assim sendo, por conta das condições inapropriadas em que se encontram a maioria desses documentos nos acervos do país, para salvaguardar e recuperar esse patrimônio, apresentamos a Crítica Textual, na sua laboriosa tarefa de edição de textos, que contribui para a preservação de documentos, haja vista não ser mais necessária a sua manipulação em virtude da publicação em novos suportes materiais.

Dentre os diversos documentos lotados no Arquivo Histórico Municipal de Rio Pardo, escolhemos realizar as edições fac-similar e semidiplomática da cópia da Provisão Real de 7 de outubro de 1809, que estabelece a primeira divisão do estado do Rio Grande do Sul. Desse modo, esperamos ter contribuído com a preservação da memória histórica da criação da cidade de Rio Pardo, além da memória linguística. Com o breve estudo linguístico sobre as variantes gráficas, demostramos como a ortografia da Provisão Real, representa a memória escrita da língua portuguesa dos períodos ortográficos fonético e etimológico. No entanto, o trabalho não se encerra por completo, pois, sem dúvida, é possível lançar outros olhares sobre esse texto.

\section{Referências bibliográficas}

ARquivo NaCional (Brasil), Dicionário Brasileiro de Terminologia Arquivística. Rio de Janeiro: Arquivo Nacional, 2005.

AuERBACH, Erich, Introdução aos estudos literários. São Paulo: Cultrix, 1970.

BELlotTO, Heloisa Liberalli, Como fazer análise diplomática e análise tipológica de documento de arquivo. São Paulo: Arquivo do Estado, Imprensa Oficial, 2002.

BRASIL, Constituição da República Federativa do Brasil: texto constitucional promulgado em 5 de outubro de 1988, com as alteracões determinadas pelas Emendas Constitucionais de Revisão nos 1 a 6/94, pelas Emendas Constitucionais nos 1/92 a 91/2016 e pelo Decreto Legislativo no 186/2008. Brasília: Senado Federal, Coordenação de Edições Técnicas, 2016.

CAMBRAIA, César Nardelli, Introdução à crítica textual. São Paulo: Martins Fontes, 2005.

CARDiA, Mirian Lopes, Conheça os acervos nominados como Memória do Mundo-Brasil da UNESCO. Disponible em línea en: http://www.arquivonacional.gov.br/br/component/content/article.html?id $=751$ :conheca-os-acervos-nominados-como-memoria-do-mundo-brasil-daunesco. [Fecha de consulta: 26 de septiembre de 2018]. 


\section{LEICI LANDHERR MOREIRA}

Costa, Evellyne Patrícia Figueiredo de Sousa; Keller, Tatiana, "Português histórico do Rio Grande do Sul: fontes para pesquisa". En: Revista do Instituto Histórico e Geográfico do Rio Grande do Sul, 153, 2017, pp. 37-51.

CostA, Miguel Ângelo Silva; REMEDI, José Martinho Rodrigues, "Em nome dos valiosos testemunhos de nossas caras tradições: a "invenção" da cidade monumento e a polêmica patrimonialização da Rua da Ladeira - Rio Pardo". En: Patrimônio e Memória, 9, 2013, pp. 31-55.

Coutinho, Ismael de Lima, Pontos de gramática histórica. Rio de Janeiro: Ao Livro Técnico, 1976.

CunHA, Antônio Geraldo, Dicionário etimológico da língua portuguesa. Rio de Janeiro: Lexikon, 2012.

GOMES, Giane de Siqueira, "O Arquivo Histórico Municipal de Viamão: particularidades de um intérprete do tempo". En: Anais do XI Encontro Estadual de História, 2012, pp. 388-402.

LOBO, Tânia Conceição Freire, "Arquivos, acervos e a reconstrução histórica do português brasileiro". En: Oliveira, Klebson; Cunha e Souza, Hirão; Soledade, Juliana (Orgs.). Do português arcaico ao português brasileiro: outras histórias. Salvador: EDUFBA, 2009, pp. 305-327.

MARQues, Ianaê Linhares; SKOlaude, Mateus Silva; Costa, Miguel Ângelo Silva; REMEDI, José Martinho Rodrigues, "Memória, História e Educação Patrimonial: revitalização do Arquivo Histórico do Município de Rio Pardo - Projeto REVITA/AHMRP”. En: Anais da $58^{a}$ Reunião Anual da Sociedade Brasileira para o Progresso da Ciência, 2006.

MeISTer, Renatta, História do Município de Rio Pardo. Disponible em línea en: https://riopardo.rs.gov.br/turismo/2017/03/21/historia-do-municipio-derio-pardo/. [Fecha de consulta: 26 de septiembre de 2018].

QueIROZ, Rita de Cássia, "Documento Baianos: Autos de curanderismo sob a lente filológica". En: Labor Histórico, 2, 2016, pp. 214-226.

TARAntino, Biagio Soares, "A Rua da Ladeira". En: Jornal de Rio Pardo, Rio Pardo, 06 fev. 1955, p. 2.

Vogt, Olgário Paulo; Romero, Maria Rosilane Zoch (Org.), Uma luz para a história do Rio Grande: Rio Pardo 200 anos: cultura, arte e memória. Santa Cruz: Editora Gazeta Santa Cruz, 2010. 